\title{
Spinal Anesthesia with Low-Dose Bupivacaine-Fentanyl Combination: a Good Alternative for Day Case Transurethral Resection of Prostrate Surgery in Geriatric Patients
}

\author{
Zeynep N Akcaboy ${ }^{1}$, Erkan Y Akcaboy ${ }^{1}$, Nevzat M Mutlu ${ }^{1}$, Nurten Serger ${ }^{1}$, Cuneyt Aksu ${ }^{1}$, Nermin Gogus ${ }^{2}$
}

Summary: Akcaboy ZN, Akcaboy EY, Mutlu NM, Serger N, Aksu C, Gogus N - Spinal Anesthesia with Low-Dose Bupivacaine-Fentanyl Combination: a Good Alternative for Day Case Transurethral Resection of Prostrate Surgery in Geriatric Patients.

Background and objective: We evaluated the effectiveness, block duration, postanesthesia care unit stay and adverse effects of using intrathecal low dose bupivacaine and fentanyl combination and compared with conventional dose prilocaine and fentanyl combination for day case transurethral resection of prostate surgery in geriatric patient population.

Materials and Methods: Sixty patients were randomized into two groups with Group B receiving 4 mg bupivacine $0.5 \%+25 \mu \mathrm{g}$ fentanyl and Group P receiving $50 \mathrm{mg}$ prilocaine $2 \%+25 \mu \mathrm{g}$ fentanyl intrathecal. Block quality and duration, postanesthesia care unit stay and adverse effects were compared.

Results: Block durations and postanesthesia care unit stay were shorter in Group B than in Group P ( $p<0.001$ in both). Hypotension and bradycardia were not seen in Group B which was significantly different than in Group P ( $p=0.024$ and $p=0.011$ respectively).

Conclusion: Intrathecal $4 \mathrm{mg}$ bupivacaine $+25 \mu \mathrm{g}$ fentanyl provided adequate spinal anesthesia with shorter block duration and postanesthesia care unit stay with stable hemodynamic profile than intrathecal $50 \mathrm{mg}$ prilocaine $+25 \mu \mathrm{g}$ fentanyl for day case transurethral resection of prostate surgery in geriatric patients.

Keywords: Anesthesia, Spinal; Bupivacaine; Prilocaine; Transurethral Resection of Prostate.

(C2012 Elsevier Editora Ltda. All rights reserved.

\section{INTRODUCTION}

Spinal anesthesia (SA) is the most commonly used anesthetic technique for transurethral resection of prostate (TURP) surgery in geriatric patient population ${ }^{1}$, which is reported to preserve cerebral function ${ }^{2}$. SA for TURP provides both analgesia and muscular relaxation, rapid onset of action, allows earlier determination of hyponatremia due to absorption of bladder irrigation fluids and also suitable for day case surgery ${ }^{3}$. However, many geriatric patients have coexisting cardiac or pulmonary diseases, so it's very important to limit the distribution of the block to prevent the possible hemodynamic and pulmonary adverse effects.

Lidocaine was a popular local anesthetic for SA in day case surgical patients, but it's known to cause transient neurological symptoms (TNS) ${ }^{4}$, which is highly reported for patients having

Received from Ankara Numune Training and Research Hospital, Ankara, Turkey.

1. MD, Department of Anesthesiology, Ankara Numune Training and Research Hospital, Ankara, Turkey

2. Assistant Professor, Department of Anesthesiology, Ankara Numune Training and Research Hospital, Ankara, Turkey

Submitted on October 12, 2011.

Approved on November 30, 2011.

Correspondence to:

Zeynep Nur Akcaboy

Alacaatı mah 3390.sok Yeni Atabilge Sitesi 2G/3 Yasamkent/Ankara/Turkey

GSM : +90 5054514665

E-mail: zakcaboy@yahoo.com surgery in the litotomy position 5 . Prilocaine has a similar potency and duration of action to lidocaine ${ }^{5,6}$ and also has been reported to have a lower incidence of TNS ${ }^{5,7}$. Also bupivacaine carries a low risk of TNS, but its long duration of action makes it unsuitable for day case surgery ${ }^{8}$. However, by using low doses of bupivacaine and intrathecal opioids together, successful anesthesia and analgesia were reported to be obtained for TURP procedures ${ }^{1,9}$. The literature search showed that there were no randomized controlled trials compairing the effects of bupivacaine with prilocaine for TURP surgery.

The purpose of this study is to compare the effectiveness of using intrathecal low dose bupivacaine-fentanyl combination with conventional dose prilocaine-fentanyl combination for day case TURP surgery in geriatric patient population. We hypothesized that, using low dose bupivacaine-fentanyl combination provides shorter duration of block duration and postanesthesia care unit (PACU) stay with better hemodynamic stability than using conventional dose prilocaine-fentanyl combination.

\section{METHODS}

After institutional ethics committee approval and obtaining written informed consent from all patients, 60 American Society of Anesthesiologists Physical Status (ASA) II-IV patients, aged 60 to 85, were scheduled for elective TURP surgery and enrolled in this prospective, randomized, double blind study. 
Patients having deformities of spinal column, and skin infections at the block area, known hypersensitivity to amide local anesthetics, abnormal coagulation profile and unwilling to accept regional anesthesia were excluded.

None of the patients were premedicated before surgery. Before performing spinal block, an intravenous (IV) cannula was inserted and IV infusion of Ringer lactate was maintained at $8 \mathrm{~mL} . \mathrm{kg}^{-1}$. hr-1 during the surgery. All spinal blocks were performed at the level of L3-L4 with a 25G Whitacre needle in the sitting position and study drugs were given in 90 seconds by the same anesthesiologist. Patients were randomly allocated into the study groups according to the list of random numbers. The study groups were as follows: Patients in Group Bupivacaine (Group $B, n=30$ ) received intrathecal $4 \mathrm{mg}$ bupicacaine $0.5 \%+25 \mu \mathrm{g}$ fentanyl and patients in Group Prilocaine (Group $\mathrm{P}, \mathrm{n}=30$ ) received $50 \mathrm{mg}$ prilocaine $2 \%+25 \mu \mathrm{g}$ fentanyl. All solutions were prepared by the anesthesiologist, who performed the spinal blocks. To provide blindness, after performing the block, this anesthesiologist did not participate in the follow-up of the patients. Block quality and duration, PACU stay and occurrence of adverse effects were observed by another anesthesiologist, who didn't know the group allocation.

Intraoperative monitoring consisted of heart rate, noninvasive blood pressure and oxygen saturation, which were recorded every 5 minutes with PETAS KMA-175 monitor (PETAS Corp; Ankara, Turkey). All patients received oxygen

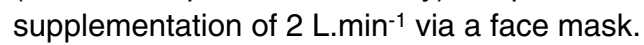

The highest dermatomal level of sensory block, the time to reach this level and the motor blockade at the time of reaching highest dermatomal level of sensory block were recorded. The higher cranial dermatome with loss of normal sensation to alcohol swabs at 2-3 consecutive tests was taken as the highest dermatomal level of sensory block. All times were recorded from the intrathecal injections of test solutions. Motor block was assessed by Bromage scores in which $0=$ no motor block, $1=$ hip blocked, $2=$ hip and knee blocked, 3= hip, knee and foot blocked. Patients were not put into litotomy position until the desired level of analgesia (T10) had been reached. Duration of block was considered as the time when Bromage score returned to 0 .

Postoperative follow-up was continued in PACU every 10 minutes until the patient was discharged. Criteria for discharge from PACU were: Stable vital signs for $>30$ minutes, orientation of patient to person, time and place, hemostasis of surgical area, absence of adverse effects, absence of pain, absence of nausea and vomiting, resolution of motor and sensory blocks.

The primary endpoints of the study were comparing the duration of spinal block and duration of PACU stay. Secondary endpoint of the study was comparing the adverse effects like hypotension, bradycardia, apnea, nausea, shivering, pruritus, block failure and pain during the operation. Failure to achieve a block level of T10 or additional analgesia request was considered as block failure. Hypotension was defined as a systolic blood pressure $<20 \%$ of preoperative value and bradycardia was defined as heart rate $<50 . \mathrm{min}^{-1}$. These adverse effects were treated by either IV bolus atropine and/or ephedrine.
On the basis of previous studies ${ }^{7}$, sample size calculation were performed and 28 patients per group were found to be sufficient to detect a 30 min difference in duration of block, with $80 \%$ power and $\alpha=0.05$. In anticipation of case failure, we included 30 patients in each group. Statistical analyses were performed using SPSS for Windows (version 11.0, SPSS Inc, Chiago, IL, USA). Data were expressed as mean and Standard Deviation (SD) or number (\%). Numerical data were analyzed by using independent samples; t test and Chi square test (Fisher's exact test) were used for categorical data. $p<0.05$ was considered significant.

\section{RESULTS}

Data from 60 patients enrolled in this study were analyzed without dropouts. Patients' demographic data and surgery durations were comparable in groups and shown in Table I.

In Table II, quality and duration of block and PACU stay were shown. Mean dermatomal level of highest sensorial block was higher in Group P than in Group B ( $p=0.001)$. But the time to reach this highest sensorial block level were comparable in groups. Motor block at the time of reaching highest sensorial block in Group B was less than in Group P $(p=0.002)$. Duration of block and PACU stay were significantly shorter in Group B than in Group P ( $p<0.001$ and $p<0.001$ respectively).

Adverse effects during the procedure were shown in Table III. In Group P, hypotension was seen in $20 \%$ of patients and bradycardia was seen in $23 \%$ of patients. Four patients needed IV bolus ephedrine and 5 patients needed IV bolus atropine in Group P. In none of the patients in Group B, hypotension and bradycardia were observed. These differences were significant between groups $(p=0.024$ and $p=0.011$ respectively). Although nausea was detected to a greater extent in Group $P$, this difference was not significant $(p=0.195)$. Other adverse effects were comparable in groups. None of the patients in either groups manifested block failure or pain during the procedure.

Table I - Patients' Demographic Data, ASA Scores and Surgery Durations in Groups

\begin{tabular}{lll}
\hline & Group B (n=30) & Group P (n=30) \\
\hline Age (years) & $69.9 \pm 9.7$ & $70 \pm 8.3$ \\
Weight (kg) & $67.6 \pm 9$ & $69.1 \pm 7.4$ \\
Height (cm) & $163.9 \pm 9.7$ & $165.8 \pm 10.3$ \\
ASA (II / III / IV) & $6 / 19 / 5$ & $7 / 19 / 4$ \\
Surgery duration (min) & $61.2 \pm 18.4$ & $63.4 \pm 17.6$ \\
\hline
\end{tabular}


Table II - Block Quality, Duration of Block and PACU Stay in Groups

\begin{tabular}{lll}
\hline & $\begin{array}{l}\text { Group B } \\
(\mathrm{n}=30)\end{array}$ & $\begin{array}{l}\text { Group P } \\
(\mathrm{n}=30)\end{array}$ \\
\hline $\begin{array}{l}\text { Highest dermatomal level of } \\
\text { sensory block }\end{array}$ & $\mathrm{T} 10(\mathrm{~T} 8-\mathrm{T} 10)$ & $\mathrm{T} 8(\mathrm{~T} 6-\mathrm{T} 10)^{*}$ \\
$\begin{array}{l}\text { Time to reach to highest } \\
\text { sensory block (min) }\end{array}$ & $7.6 \pm 1.3$ & $7.1 \pm 1.9$ \\
$\begin{array}{l}\text { Motor block at the time of } \\
\text { reaching highest sensory block }\end{array}$ & $1(0-3)$ & $2(1-3)^{*}$ \\
$\begin{array}{l}\text { Duration of block (min) } \\
\text { Duration of PACU stay (min) }\end{array}$ & $1108.3 \pm 19$ & $8.0 \pm 21.3^{*}$ \\
\hline
\end{tabular}

*p $<0.05$ Group B vs Group P.

Table III - Adverse Effects in Groups

\begin{tabular}{lll}
\hline & $\begin{array}{l}\text { Group B } \\
(\mathrm{n}=30)\end{array}$ & $\begin{array}{l}\text { Group P } \\
(\mathrm{n}=30)\end{array}$ \\
\hline Hypotension & 0 & $6^{*}$ \\
Bradycardia & 0 & $7^{*}$ \\
Pruritus & 4 & 5 \\
Nausea & 1 & 5 \\
Shivering & 0 & 0 \\
Apnea & 0 & 0 \\
Block failure & 0 & 0 \\
Pain during procedure & 0 & 0 \\
\hline
\end{tabular}

* $p<0.05$ Group B vs Group P.

\section{DISCUSSION}

This study showed that, by using low dose bupivacaine $0.5 \%$ $(4 \mathrm{mg})$ with $25 \mu \mathrm{g}$ fentanyl, an adequate SA with shorter block duration and PACU stay can be obtained than using conventional dose prilocaine $2 \%(50 \mathrm{mg})$ with $25 \mu \mathrm{g}$ fentanyl for TURP surgery. Better hemodynamic stability can also be provided which is especially very important in geriatric patient population.

Previous studies reported that a spinal block higher than L1 would be adequate during TURP surgery, when bladder pressure is monitored and kept low ${ }^{10}$. However, when intravesical pressure monitoring was not available - as in our study - a sensory block extending to T10 dermatome is necessary ${ }^{11}$. As known, systemic hypotension and bradycardia are the most common side effects during central neural blocks ${ }^{12}$. Marked hypotension can be deleterious especially in geriatric patients with limited cardiac reserve ${ }^{12-14}$. High incidence of coronary disease in geriatric patients increases the risk of myocardial ischemia due to hypotension ${ }^{14}$. Aside from age, a high level of block is another important factor in the development of hypotension during $S A{ }^{15}$. In geriatric patients, gradual degeneration of peripheral and central nerves, changes in anatomical configuration of the lumbar and thoracic spine and the decrease in cerebrospinal fluid volume may contribute to this increase in sympathetic block level ${ }^{15}$.

Short durations of motor and sensorial block with reduced PACU stays are desired properties, which will provide early discharge to home in day case surgeries. For this purpose, the anesthesiologist and urologist have to communicate effectively; the surgeon should inform the anesthesiologist how large the gland is, how much resection time is needed and if patient should be discharged from hospital early. In this way, the best local anesthetic agent with appropriate duration of action can be used by the anesthesiologists for SA.

In literature, many different local anesthetics have been used in SA for TURP surgery. The most popular local anesthetic in day case surgical patients is lidocaine but high incidence of TNS after intrathecal lidocaine led to the search for an alternative to lidocaine ${ }^{5}$. Prilocaine was reported as such in day case surgeries with low incidence of TNS ${ }^{5-7}$. However, marked hypotension and bradycardia were reported in intrathecal prilocaine use ${ }^{7,16}$. Bupivacaine has a low risk of TNS as well ${ }^{8}$. Nonetheless, if used in conventional doses in day case surgeries, its main disadvantages are long duration of action and recovery and hemodynamic adverse effects like hypotension ${ }^{8}$. Many different attempts have been attempted to decrease the block duration of bupivacaine, like lowering the dose and adding adjuvant drugs 1,9,5,17,18. Intrathecal opioids are known to enhance analgesia of subtherapeutic doses of local anesthetics ${ }^{10,12,19}$. Thus, successful SA can be achieved by combining intrathecal opioids with low doses of local anesthetics that would be inadequate when used independently $12,19,20$. Using low doses of local anesthetics could shorten the block duration and its recovery and could also prevent the undesired hemodynamic adverse effects.

Bupivacaine $(4 \mathrm{mg})$ with $25 \mu \mathrm{g}$ fentanyl was reported as providing adequate analgesia for TURP in the study of Kararmaz et al. ${ }^{1}$ In this study, they compared this low-dose bupivacaine usage with the conventional dose of bupivacaine $(7.5 \mathrm{mg})^{1}$. In our study, we attempt to demonstrate that, by using low dose bupivacaine (4 mg) with $25 \mu \mathrm{g}$ fentanyl, we could provide adequate SA with short block duration and PACU stay and a stable hemodynamic profile. It was also compared compared this with conventional dose prilocaine $(50 \mathrm{mg})$ with $25 \mu \mathrm{g}$ fentanyl, frequently used for day case surgeries ${ }^{7}$. In the group where bupivacaine was used, a mean block level of T10 was obtained, which is consistent with the study of Kararmaz et al. ${ }^{1}$ Although the highest sensorial dermatomal level achieved is lower than in other studies in which bupivacaine was used in higher doses, we could provide adequate anesthesia for TURP surgery without failed blocks or pain during the procedure. By using low doses of bupivacaine, we also provided shorter block durations and PACU stays when compared to those studies ${ }^{9,12,21}$, as well as significantly shorter than the group where prilocaine was used.

Biboulet et al. ${ }^{22}$ demonstrated that the incidence of hypotension was $40 \%$ in geriatric patients when the dose of intrathecal bupivacaine was $5 \mathrm{mg}$. In our study, hypotension 
and bradycardia were not observed in Group B; but hypotension was bserved in $20 \%$ and bradycardia was observed in $23 \%$ of patients in Group $P$, which is significantly more than Group B.

Nausea, observed after SA, can be caused either by hypotension or intrathecal fentanyl ${ }^{15}$. Although not statistically different, more patients in Group P experienced nausea in our study, which can be due to higher incidence of hypotension in this group. Shievering - which is known to increase oxygen consumption - can result in morbidity in patients with limited cardiopulmonary reserve ${ }^{23}$. There was no shivering in any of our patients. This could be due to the addition of intrathecal fentanyl, which is reported to decrease shivering in geriatric patients ${ }^{23}$. We observed pruritus - the most common side effect of intrathecal fentanyl usage - in $15 \%$ of our patients.

In conclusion, adequate SA can be provided by using $4 \mathrm{mg}$ bupivacaine and $25 \mu \mathrm{g}$ fentanyl combination with shorter block duration and PACU stay when compared with $50 \mathrm{mg}$ prilocaine and $25 \mu \mathrm{g}$ fentanyl combination for day case TURP surgeries. We also observed that a stable hemodynamic profile with low-dose bupivacaine becomes advantageous, especially in geriatric patients. 


\section{REFERENCES}

1. Kararmaz A, Kaya S, Turhanoglu S, Ozyılmaz MA - Low dose bupivacaine-fentanyl spinal anesthesia for transurethral prostatectomy. Anaesthesia, 2003;58:526-530.

2. Hole A, Terjesen $\mathrm{T}$, Breivig $\mathrm{H}$ - Epidural versus general anesthesia for total hip artroplasty in elderly patients. Acta Anaesthesiol Scand, 1980;24:279-287.

3. Rubin AP - Spianal anesthesia - Em: Wildsmith JA ed. Principles and Practice of Regional Anesthesia. London, UK: Churhill Livingstone; 1998, pp 70-80.

4. Hampl K, Scheneider M, Ummenhofer W, Drewe J - Transient neurologic symptoms after spinal anesthesia. Anesth Analg, 1995;81:11481153.

5. Ostgaard G, Hallaraker O, Ulveseth OK, Flaaten $\mathrm{H}-\mathrm{A}$ randomized study of lidacaine and prilocaine for spinal anesthesia. Acta Anaesthesiol Scand, 2000;44:436-440.

6. De Weert K, Traksel M, Gielen M, Slappendel R, Weber E, Dinksen $\mathrm{R}$ - The incidence of transient neurological symptoms after spinal anesthesia with lidocaine compared to prilocaine. Anaesthesia, 2000;55:1020-1024.

7. Hendriks MP, de Weert CJM, Snoeck MMJ, Hu HP, Pluim MAL, Gielen MJM - Plain articaine or prilocaine for spinal anesthesia in day case knee arthroscopy: a double blind randomized trial. $\mathrm{Br} \mathrm{J}$ Anaesth, 2009;102:259-263.

8. Liu SS, Ware PD, Allen HW, Neal JM, Pollock JE - Dose response characteristics of spinal bupivacaine in volunteers. Anesthesiology, 1996;85:729-736.

9. Akcaboy EY, Akcaboy ZN, Gogus N - Low-dose levobupivacaine $0.5 \%$ with fentanyl in spinal anesthesia for transurethral resection of prostate surgery. JRMS, 2011;16:68-73.

10. Beers RA, Kane PB, Nsouli I, Krauss D - Does a mid-lumbar block level provide adequate anesthesia for transurethral prostatectomy? Can J Anaesth, 1994;41:807-812.

11. Malhotra V, Diwan S - Anesthesia for the renal and genitourinary systems. Em: Miller RD ed. Anesthesia. Philadelphia, USA: Churchill Livingstone; 2000: 1949.

12. Kuusniemi KS, Pihlajamaki KK, Pitkanen MT, Helenius HY, Kirvela $\mathrm{OA}$ - The use of bupivacaine and fentanyl for spinal anesthesia for urologic surgery. Anesth Analg, 2000;91:1452-1456.

13. Critchley LA - Hypotension, subarachnoid block and the elderly patient. Anaesthesia, 1996;51:1139-1143.

14. Rooke GA, Freund PR, Jacobson AF - Hemodynamic response and change in organ blood volume during spinal anesthesia in elderly men with cardiac disease. Anesth Analg, 1997;85:99-105.

15. Erdil F, Bulut S, Demirbilek S, Gedik E, Gulhas N, Ersoy MO - The effects of intrathecal levobupivacaine and bupivacaine in the elderly. Anaesthesia, 2009;64:942-946. 
16. Reisli R, Celik S, Tuncer S, Yosunkaya A, Otelcioglu S - Anesthetic and hemodynamic effects of continuous spinal versus continuous epidural anesthesia with prilocaine. Eur J Anaesthesiol, 2003;20:26-33.

17. Nair GS, Abrishami A, Lernitte J, Chung F - Systematic review of spinal anesthesia using bupivacaine for ambulatory knee arthroscopy. Br J Anaesth, 2009;102:307-315.

18. Owen MD, Ozsarac O, Sahin S, Uckunkaya N, Kaplan N, Magunaci I - Low-dose clonidine and neostigmine prolong duration of intrathecal bupivacaine-fentanyl for labor analgesia. Anesthesiology, 2000;92:361-366.

19. Sarvela PJ, Halonen PM, Korttila KT - Comparison of $9 \mathrm{mg}$ of intrathecal plain and hyperbaric bupivacaine both with fentanyl for cesarean delivery. Anesth Analg, 1999;89:1257-1262.

20. Wang C, Chakrabarti MK, Whitwam JG - Specific enhancement by fentanyl of the effects of intrathecal bupivacaine on nociceptive afferent but not on sympathetic efferent pathways in dogs. Anesthesiology, 1993;79:766-773.

21. Goel S, Bhardwaj N, Grover VK - Intrathecal fentanyl added to intrathecal bupivacaine for day case surgery: a randomized study. Eur $\mathrm{J}$ Anaesthesiol, 2003;20:294-297.

22. Biboulet $P$, Deschodt $J$, Aubas $P$, Vacher $E$, Chauvet $P$, D'Athis $F$ - Continuous spinal anesthesia: does low-dose plain or hyperbaric bupivacaine allow the performance of hip surgery in the elderly? Reg Anesth Pain Med, 1993;18:170-175.

23. Chow TC, Cho PH - The influence of small dose intrathecal fentanyl on shivering during transurethral resection of prostate under spinal anesthesia. Acta Anaesth Sinica, 1994;32:165-170. 